\title{
PARTISIPASI PETERNAK SAPI DALAM PENYULUHAN DI DESA TONDEGESAN SATU KECAMATAN KAWANGKOAN KABUPATEN MINAHASA
}

\author{
Venessa J. M. Tulong, A. A. Sajow, G. D. Lenzun, S. O. B. Lombogia* \\ Fakultas Peternakan Universitas Sam Ratulangi Manado 95115
}

\begin{abstract}
ABSTRAK
Partisipasi peternak sangatlah penting dalam kegiatan penyuluhan karena dapat membantu peternak endapatkan informasiinformasi yang penting mengenai pengembangan ternak sapi tersebut.Tujuan penelitian ini adalah mengetahui partisipasi peternak sapi dalam penyuluhan di Desa Tondegesan Satu Kecamatan Kawangkoan Kabupaten Minahasa. Penelitian ini dilakukan dengan analisis Miles dan Huberman mengunakan metode survey Responden yang dipilih dengan menggunakan metode purposive kepada peternak yang pernah mengikuti kegiatan penyuluhan di Desa Tondegesan Satu Kecamatan Kawangkoan Kabupaten Minahasa berjumlah 30 responden dan Pengumpulan data dilakukan dengan wawancara langsung kepada peternak sapi dengan bantuan kuesioner. Hasil penelitian ini menunjukan bahwa partisipasi dalam perencanaan, partisipsi dalam kegiatan, dan partisipasi dalam pemanfaatan hasil berkategori baik.
\end{abstract}

Kata kunci : Partisipasi, Penyuluhan, Peternak sapi

Korespondensi (corresponding author): Email: lombogiastanly@yahoo.co.id
ABSTRACT

\begin{tabular}{lrrr} 
PARTICIPATION & OF & \multicolumn{2}{c}{ CATTLE } \\
FARMERS IN & COUNSELING AT \\
TONDEGESAN & SATU VILLAGE \\
KAWANGKOAN & & DISTRICT \\
MINAHASA & & REGENCY.The
\end{tabular}
participation of cattle farmers are very important in counseling activity because it can help the breeder to get the important informations about development of farms cow. The purpose of this study was to determine information about villages in Tondegesan Satu Village, Kawangkoan District, Minahasa Regency. This research was run by Miles and Huberman analysis using survey methods. espondents were selected using purposive to breeders methods that once had activities in Tondegesan Satu Village Kawangkoan District, Minahasa District amount 30 respondents and data collection was done by direct interviews with cattle farmers by the help of questionnaires. The results of this study is indicate that the participation in planning, participation in activity and participation in the utilization of results is great.

Keywords : Participation, Counseling, CowFarmers

\section{PENDAHULUAN}

Indonesia adalah negara kepulauan terbesar di dunia, jumlah penduduk yang banyak merupakan potensi yang besar tetapi juga merupakan beban yang berat. Kebutuhan pangan, perumahan, pendidikan, kesehatan, dan yang paling 
mendesak adalah kebutuhan lapangan kerja baru yang banyak harus tersedia setiap tahun.Pembangunan peternakan memiliki arti penting dan strategis dalam memenuhi kebutuhan masyarakat, baik dari segi pendapatan maupun kebutuhan pangan yang terus meningkat seiring meningkatnya jumlah penduduk dari tahun ketahun. Sektor peternakan mengalami permasalahan, salah satunya permasalahan yang timbul adalah: berkurangnya partisipasi dari peternak.Penyuluhan peternakan adalah pemberdayaan peternak dan keluarganya beserta masyarakat pelaku agribisnis melalui kegiatan pendidikan non formal dibidang peternakan agar mereka mampu menolong dirinya sendiri baik dibidang ekonomi, social maupun politik sehingga peningkatan pendapatan dan kesejahteraan mereka dapat dicapainon formal atau penyuluhan.Partisipasi peternak dalam penyuluhan dapat memberikan gambaran akan keinginan, kemauan dan kesempatan yang ada baik pada diri peternak maupun penyuluh, dalam bentuk parisipasi dalam keiatan dan partisipasi dalam pelaksanaan Dwiningrum (2010).

\section{METODE PENELITIAN}

\section{Waktu Dan Tempat}

Penelitian ini dilaksanakan pada tanggal 15 juli sampai dengan 13 agustus
2018 di Desa Tondegesan Satu Kecamatan Kawangkoan Kabupaten Minahasa.

\section{Metode Penentuan Narasumber}

Penentuan sampel ditentukan secara sengaja (purposeive) yaitu suatu metode yang berdasarkan atas pertimbangan-pertimbangan tertentu.Dasar pertimbangan yang dipakai dalam memilih narasumber ialah peternak sapi yang pernah mengikuti kegiatan penyuluhan tentang ternak sapi di Desa Tondegesan Satu Kecamatan Kawangkoan Kabupaten Minahasa.

\section{Sumber data}

Data yang digunakan dalam penelitian ini adalah data primer dan data sekunder. Data primer yaitu data yang diperoleh dari wawancara langsung dari objek penelitian atau narasumber dilakukan dengan menggunakan kuesioner kepada peternak sapi yang ada di Tondegesan Satu, sedangkan data sekunder adalah data yang diperoleh dari instansi pemerintahan dari Tondegesan Satu, BPS (Badan Pusat Statistik) Kecamatan Kawangkoan dan BP3K/BP4K Kecamatan Kawangkoan.

\section{Definisi Variabel Dan Pengukuran}

Variabel yang diukur dalam penelitian ini adalah partisipasi dalam perencanaan, partisipasi dalam kegiatan dan partisipasi dalam pemanfaatan hasil.Variabel yang akan diukur dijabarkan 
Zootec Vol. 39 No. 2 : 184-193 (Juli 2019) pISSN 0852 - 2626 eISSN 2615 - 8698

menjadi indikator variabel dan menjadi parameter. Parameter ini digunakan sebagai tolak ukur dalam menyususn daftar pertanyaan pada kuisioner.

\section{Analisis Data}

Analisis yang digunakan dalam penelitian ini adalah ama;isis deskripif, yang mengacu pada anaisis data yang di kemukakan Miles dan Huberman (1984) bahwa aktivitas dalam analisis data kuantitatif dilakukan secara interaktif dan berlangsung secara terus menerus sampai tuntas, sehingga datanya jenuh. Pada saat wawancara peneliti sudah melakukan analisis terhadap jawaban yang diwawancarai, bila jawaban yang diwawancarai setelah analisis terasa belum memuasaka, maka peneliti akan melanjutkan pertanyaan lagi sampai tahap tertentu diperoleh data yang di anngap kridibel.

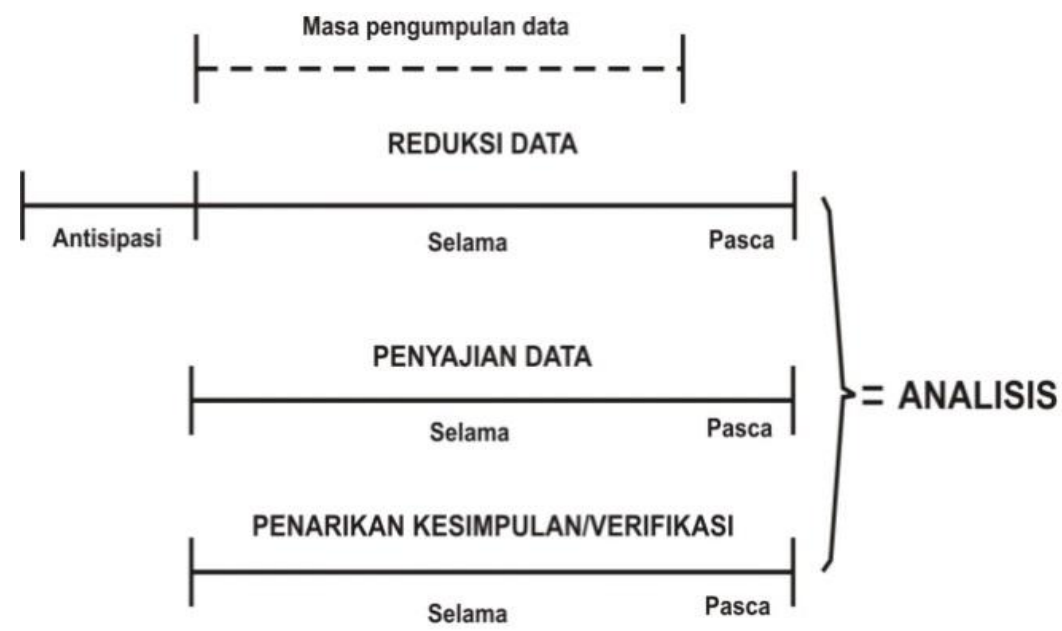

Gambar 1. Komponen dalam analisis data 


\section{HASIL DAN PEMBAHASAN}

\section{Karakteristik Responden}

Responden yang diambil dalam penelitian ini adalah peternak sapi yang pernah mengikuti kegiatan penyuluhan di desa Tondegesan Satu berjumlah 30 orang.Umur, tingkat pendidikan, jumlah ternak diamati secara deskriptif sedangkan untuk partisipasi dalam perencanaan, kegiatan dan pemanfaatan hasil.

\section{Distribusi Responden Menurut Umur}

Tingkat umur memberikan pengaruh terhadap kapasitas dan kemampuan belajar seseorang. Seseorang yang relatif muda dan masih produktif akan memiliki tingkat kecepatan yang lebih baik dibandingan dengan seseorang yang sudah lanjut usia atau masih sangat kanak-kanak. Dari hasil penelitian menunjukan bahwa kisaran umur petani cukup bervariasi antara 30-70 tahun. Kebanyakan petani peternak responden berumur 40-60 tahun, yaitu sebanyak 21 orang (70\%) dan paling rendah $>60$ tahun sebanyak 4 orang $(13,34 \%)$. Hal ini berarti ratarata petani peternak di desa Tondegesan Satu, berada pada kelompok usia produktif untuk melakukan pekerjaan atau menjalankan usahanya. Menurut Rogers (1986) semakin muda seseorang, dan ada dalam usia yang produktif akan lebih responsif dalam menerima inovasi dibandingkan dengan orang yang telah lanjut.

\section{Tabel 1.Distribusi Responden Menurut Umur}

\begin{tabular}{llll}
\hline No & Umur Responden & Jumlah (orang) & Presentase (\%) \\
\hline 1. & $<40$ & 5 & 16,6 \\
2. & $40-50$ & 21 & 70 \\
3. & $>60$ & 4 & 13,34 \\
\hline & & 30 & 100
\end{tabular}

\section{Tabel 2. Tingkat Pendidikan}

\begin{tabular}{llll}
\hline No & Tingkat Pendidikan & Jumlah (Orang) & Presentase (\%) \\
\hline 1. & Tingkat Lulusan SD & 15 & 50 \\
2. & Tingkat Lulusan SMP & 8 & 26,67 \\
3. & Tingkat Lulusan SMA & 7 & 23,33 \\
\hline & & 30 & 100 \\
\hline
\end{tabular}




\section{Tingkat Pendidikan}

Tingkat pendidikan dari petani peternak juga menentukan keberhasilan usaha peternakan karena dengan berbekal pengetahuan yang cukup melalui jenjang pendidikan maka akanturut mempengaruhi produktivitas usaha peternakan.Hasil penelitian menunjukan bahwa data pendidikan peternak di desa Tondegesan satu adalah SD (50\%), SMP (26,67\%), SMA $(23,33)$. Tingkat pendidikan di desa Tondegesan satu masih tergolong rendah. Rendahnya tingkat pendidikan peternak tersebut akan menyebabkan peternak kurang bijaksana dalam mengambil keputusan dan cenderung lambat menerima inovasi baru akhirnya akan menentukan keefesian peternak dalam berusaha Suryana (2009). Tetapi menurut penelitian yang dilakukan kebanyakan peternak di desa Tondegesan Satu sangat bijak sana dalam mengambil keputusan dikarenakan pengalaman beternak mereka sudah cukup
lama.Pengembangan profesionalitas juga berkaitan dengan jenjang karier, sehingga seseorang akan berharap menduduki jabatan tertentu bila telah memperoleh suatu keahlian (Ani dan jahi 2006).

\section{Jumlah Kepemilikan Ternak}

Pada umumnya usaha ternak sapi di Desa Tondegesan satu Kecamatan Kawangkoan Kabupaten Minahasa merupakan peternak tradisional. Adapun klasifikasi ternak sapi yang dipelihara oleh peternak di desa Tondegesan Satu hasil dari kepemilikan sapi menjadi 3 bagian yaitu (1-3 ekor dengan presentase $66,67 \%, 4-5$ ekor dengan presentase $26,67 \%$ dan $>6$ ekor dengan prensentase $6.66 \%$.Hal ini dibuktikan dengan hasil wawancara beberapa peternak tahun 2018 pada umumnya sebagian besar peternak memiliki populasi ternak berkisar 15ekor.Menurut Siregar (2009) bahwa petani yang memiliki ternak 1-2 ekor sapi potong merupakan usaha ternak sapi yang tradisional. 
Tabel 3.Klasifikasi Responden Berdasarkan Jumlah Kepemilikan Ternak Sapi

\begin{tabular}{llll}
\hline No & Jumlah Kepemilikan Ternak & Jumlah (Orang) & Presentase (\%) \\
\hline 1. & $1-3$ Ekor & 20 & 66,67 \\
2. & $4-5$ Ekor & 8 & 26,67 \\
3. & $>6$ Ekor & 2 & 6,66 \\
\hline & 30 & 100 \\
\hline
\end{tabular}

Tabel 4.Partisipasi Peternak Dalam Perencanaan Kegiatan Penyuluhan

\begin{tabular}{lllll}
\hline No & Indikator & Setuju & $\begin{array}{l}\text { Kurang } \\
\text { setuju }\end{array}$ & Tidak setuju \\
\hline 1. & $\begin{array}{l}\text { Pengambilan keputusan } \\
\text { Mengenai rencana }\end{array}$ & 25 & 5 & - \\
& $\begin{array}{l}\text { penyuluhan (orang) } \\
\text { Penentuan waktu yang }\end{array}$ & 30 & - & - \\
& tepat(orang) & & & \\
\hline
\end{tabular}

\section{Partisipasi Dalam Perencanaan}

Partisipasi dalam perencanaan penyuluhan menyangkut keterlibatan peternak dalam pengambilan keputusan mengenai perencanaan penyuluhan yang akan dilaksanakan Choen dan Uphoff (1980). Dalam tahapan penyuluhan tingkat penglibatkan peternak dalam memutuskan rencana penyuluhan sangat penting guna berjalannya kegiatan penyuluhan.Dari observasi dan hasil wawancara tersebut, partisipasi dalam memutuskan rencana penyuluhan adalah sangat tinggi, partisipasi yang tinggi dalam perencanaan penyuluhan utamanya dalam pengambilan keputusan menyebabkan penyuluhan yang dilaksanakan lebih memenuhi kebutuhan peternak. Dari hasil wawancara dalam penentuan waktuadalah sangat tinggi, Penentuan waktu penyuluhan juga merupakan hal penting dalam menentukan keberhasilan proses penyuluhan. Penentuan waktu yang fleksibel dan sesuai dengan keadaan peternak, serta metode yang menciptakan perasaan nyaman dalam proses penyuluhan, mampu 
meningkatkan keberhasilan sebuah proses pembelajaran termasuk penyuluhan (Knowles, 1996. Fleksibel waktu yang diperlukan mengingat peternak merupakan orang dewasa yang memiliki tanggung jawab yang beragam, yaitu tidak hanya pada usahataninya, tetapi dia juga kepala rumahtangga, pemimpin dan mempunyai tanggungjawab lainya, sehingga waktu penyuluhan harus sesuai dengan kesempatan peternak untuk berpartisipasi.

\section{Partisipasi Dalam Pelaksanaan Penyuluhan}

Partisipasi dalam pelaksanaan penyuluhan terkait dengan partisipasi dalam proses penyuluhan yang dilaksanakan bagi peternak. Penyediaan tempat pelaksanaan penyuluhan dipenuhi oleh penyuluh yang membuat kegiatan penyuluhan tersebut, penyuluhan biasanya diadakan di BP3K desa tondegesan.atau disalah satu rumah peternak yang bersedia memberikan tempat dalam hal ini rumah dari ketua kelompok peternak di desa Tondegesan Satu.Kesempatan mengemukakan pendapat selama proses penyuluhanberlangsung. Kesempatan tersebut utamanya diperoleh pada penyuluhan yang sifatnya temporer, peternak memiliki kesempatan yang cukup untuk menyampaikan pendapat tentang apa yang sedang dibahas dan di desa Tondegesan terdapat 5 orang peternak yang sering menyampaikan pendapat dengan penyuluh yaitu pengurus dari kelompok ternak dan dari kesimpulan dari pertanyaanpertanyaan dan jawaban yang diberikan penyuluh dibahas di pertemuan kelompok ternak dan didiskusikan oleh semua anggota.

Tabel 5. Partisipasi Dalam Pelaksanaan Kegiatan Penyuluhan

\begin{tabular}{clccc}
\hline No & \multicolumn{1}{c}{ Indikator } & Sering & Jarang & Tidak pernah \\
\hline 1. & $\begin{array}{l}\text { Membantu menyediakan tempat } \\
\text { pelaksanaan penyuluhan(oramg) }\end{array}$ & - & 1 & 29 \\
2. & Memberikan pendapat (orang) & 15 & - & 15 \\
\hline
\end{tabular}


Zootec Vol. 39 No. 2 : 184-193 (Juli 2019) pISSN 0852 - 2626 eISSN 2615 - 8698

Tabel 6. Partisipasi Dalam Pemanfaatan Hasil

Inikator Kategori Jumlah (oramg)

Setuju 30

Berinteraksi dengan Kurang Setuju

peternak lainnya

Tidak Setuju

Tabel 7.Partisipasi Dalam Pemanfaatan Hasil

\begin{tabular}{llccc}
\hline No & \multicolumn{1}{c}{ Indikator } & Baik & Kurang Baik & $\begin{array}{c}\text { Tidak } \\
\text { Baik }\end{array}$ \\
\hline 1. & $\begin{array}{l}\text { Bagaimana bibit yang } \\
\text { dihasilkan (orang) }\end{array}$ & 30 & - & - \\
2. & $\begin{array}{l}\text { Bagaimana pakan yang } \\
\text { diberikan(orang) }\end{array}$ & 30 & - & - \\
3. & $\begin{array}{l}\text { Bagaimana pemeliharaan } \\
\text { yang diterapkan (orang) }\end{array}$ & 30 & - & - \\
\hline
\end{tabular}




\section{Partisipasi Dalam Pemanfatan Hasil}

Partisipasi dalam pemanfaatan hasil terkait dengan pemanfaatan hasil penyuluhan oleh peternak akibat pelaksanaan penyuluhan.Dalam penelitian ini terdapat dua indikator terkait dengan pemanfaatan hasil penyuluhan yaitu manfaat sosial dari penyuluhan sebagaimana diungkapkan oleh Korma (2003) dan pemanfaatan bibit, pakan, manajemen.Manfaat sosial yang diperoleh oleh peternak dari pelaksanaan penyuluhan adalah adanya kesempatan bagi peternak dalam berinteraksi dengan peternak lainnya saling tukar menukar informasi dan pengalaman dalam melaksanakan usahanya. Hal ini sejalan dengan apa yang dikemukakan oleh Kroma (2003), bahwa melalui hubungan sosial, petani dapat belajar diluar komunitasnya melalui sharing informasi dan mengalaman, melalui pertukaran informasi antarpeternak dapat pula menjadi media penyebaran teknologi yang efektif, sehingga mendorong adopsi teknologi semakin tinggi.Bibit ternak yang berkualitas baik dapat dilihat dari tingkat produktivitas, antara lain berupa pertambahan berat badan per hari pada ternak potong, produksi susu per rkor per laktasi, dan produksi telur per siklus usaha. Pakan merupakan aspek penting dalam usaha ternak selain bibit. Sebagian besar peternak masih menggunakan pakan sesuai dengan potensi yang ada pada umumnya berasal dari rumput alam yang dicari atau bahkan dengan manajemen pemberian pakan yaitu pemanfaatan sumberdayasumberdaya dalam proses pemberian pakan untuk mengoptimalkan bahan pakan dalam memperoleh hasil ternak yang baik Wardoyo dan Risdianto (2011).melepas ternak pada padang pengebalaan.Dalam usaha sapi potong ada hal yang perlu diperhatikan yaitu, pemelihaaan yang mencakup manajemen perkandangan, kandang dapat dibuat dalam bentuk ganda atau tunggal, tergantung dari jumlah sapi yang dimiliki.Lokasi yang ideal untuk membangun kandang adalah daerah yang letaknya cukup jauh dari pemukiman penduduk.Pada umumnya di Kabupaten Minahasa desa Tondegesan satu ternak sapi potong masih bersifaat eksentif yakni ternak sapi dilepas pada siang hari di lahan perkebunan dan pada malam hari dibawah pulang kerumah untuk di kandangkan.Kandang yang dibuat sangat sederhana, yang prinsipnya bisa melindungi ternak sapi dari cuaca dan aman dari pencurian.

\section{KESIMPULAN}

Partisipasi peternak sapi dalam penyuluhan di Desa Tondegesan Satu Kecamatan Kawangkoan Kabupaten Minahasa dari partisipasi perencanaan dalam penyuluhan, partisipasi dalam pelaksanaan dan partisipasi dalam 
pemanfaatan hasil dalam kategori setuju dan untuk bibit, pakan, pemeliharaan masing-masing berada dalam kategori baik.

\section{Daftar Pustaka}

Ani, J. Jahi, A. 2006.Kinerja penyuluh pertanian dibeberapa Kabupaten di Provinsi Jawa Barat. Jurnal Penyuluhan. 2 (2):105-106.

Cohen, J. M. and M. T. Uphoff. 1980. Participation's place in rural development soeking thorugh specificity world develop. Jounal Of International Agricullural. 8 (3) :213-235.

Dwiningrum. 2010. Desentralisasi dan partisipasi masyarakat dalam pendidikan. jurnal peternakan. 2 (1) : 94-95.

Knowles, M. 1996. The Adult Learner: A Neglected Species. Gulf Publishing, Houston.

Korma, M. 2003. Participation and social learning supporting farmer innovation in central ghana. Jounal Of International Agricullural And Extension Education. 10 (1): 43-49.

Miles dan Huberman. 1984. Qualitative Data Analysis a Sourcebook of New Methode. London: Sege Publications.

Rogers, E. M. 2003. Diffusion Of Innovations. Fifth Ed.New York Press. New York

Siregar, H. J. 2009. Pengaruh Pemberian Vitamin C, terhadap Jumlah Sel Leyding dan Jumlah Sperma Mencit Jantan Dewasa Yang Dipapari MSG. M. Biomed. Tesis. Universitas Sumatera Utara. Medan.
Suryana. 2009. Pengembangan usaha ternak sapi potong berorientasi agribisnis dengan pola kemitraan. Jurnal Litbang Pertanian. 28 (1) : 31-32.

Wardoyo dan Risdianto, A. 2011. Studi manajemen pembibitan dan pakan sapi peternakan ongole di loka penelitian sapi potong Grati Pasuruan. Jurnal Ternak. 2 (1): 1-7 
Zootec Vol. 39 No. 2 : 184-193 (Juli 2019) pISSN 0852-2626 eISSN 2615 - 8698 